\title{
CHANGING LANDSCAPE OF RESEARCH TRADITIONS: PARADIGMATIC AND NARRATIVE ORIENTATIONS
}

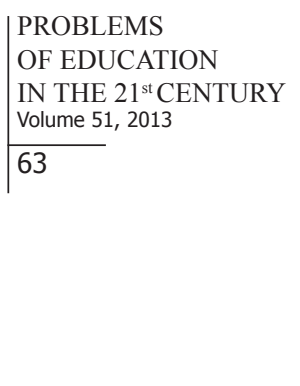

\author{
Dzintra Ilisko \\ Daugavpils University, Latvia \\ E-mail: dzintra.ilisko@du.Iv
}

\begin{abstract}
The objective of the research is to elaborate on changing research traditions in one of the institutions in Latvia. The choices of research traditions highlight changes towards more qualitative research traditions: collaborative action research and narrative research methodologies. Action research tradition opens new horizons for the research as an active, open - minded and cooperative research that affirms the importance of experimentation, and emphasizes a continual growth in researchers' awareness leading to 'phronesis'. By the qualitative research methodology the authors attempt to explore the role of the researcher, what University researchers view as significant in framing their professional landscape as a result of the use of collaborative action research and other types of qualitative research. The results: Research highlights changes and tensions in researchers' willingness to accept greater ambiguity, uncertainties, and practice of exercising judgments within the qualitative inquiry tradition and teaching process instead of complete reliance on predetermined rules and procedures. Various tensions between paradigmatic and narrative orientations towards teaching and within teachers'lives are explored and ultimately seen as contributing in complex and ambiguous ways to researchers' professional knowledge landscape. The study also highlights the co - existence of both equally legitimate epistemological research traditions - positivism, and costructivism, as an alternative in educational research in Latvia. The evidence gained in this small scale study indicates to the emergence of the qualitative tradition grounded in constructivism.

Key words: changes in research traditions, narrative ways of knowing, participative action research.
\end{abstract}

\section{Introduction}

After the collapse of the Soviet Union in 1989, Latvia, like other Central European countries, has undergone immense transition in all spheres of life. The transitions took place from socialism to a market economy or a 'wild capitalism,' from a centralized government towards decentralization, from the authoritarian methods of teaching to a newly acquired but yet not understood democratic forms of teaching, from atheism as a state ideology to religious freedom, from a closed society to a globalized world. Teachers and University lecturers needed to learn to adjust to democracy that promoted diversity of opinions and social participation in the decision making processes after the life of 50 years in culture of silence. The major features of Soviet system can be described as: the ideologized context of education, domineering Marxism - Leninism ideology, collective consciousness, unified teaching methods, education of a 'new Soviet person' educated to fit the existing system (Kestere, 2005). The culture of political silence caused teachers' inability to evaluate social and political processes critically caused the feelings of powerlessness and disappointment for the ideals of democratic government (Rubane, 2010).

Teachers needed to adjust to new circumstances of a constantly changing environment. Teachers found themselves in the situation where they needed to learn and relearn in order to adjust to new circumstances. Rubane, Geikina \& Svence (2008) identifies the following aspects of a socio - political culture in a post - Soviet Latvia: lack of democratic personalities, inability 
PROBLEMS

OF EDUCATION

IN THE $21^{\text {st }}$ CENTURY

Volume 51,2013

to accept democratic values, conviction about one true road, or the truth, inability to influence political and social changes, and civic passivity. First years of changes brought some liberalization of education, but soon education turned back to the authoritarian mood and encumbered the democratization processes in the country. New approaches in education and research were perceived quite sceptically by teachers and caused nostalgia for values of order and stability of the Soviet educational system. Many teachers graduated Universities in the Soviet educational system and could not solve the challenges of the democratic school. They live in a reality of ambiguity of conflicting ideologies. The challenge is to go beyond functionalism to consider the conflict, rupture and qualitative changes, and to liberate themselves from habitual ways of thinking.

\section{Paradigmatic Changes in Research Traditions}

Research paradigm can be viewed as the researcher's epistemological, ontological and methodological stance. The domineering and more preferred research paradigm in the Soviet research tradition was positivism which in itself is not wrong philosophy with its ontology to view reality from the perspective of the objectivist epistemology and experimental methodology where everything needed to be given prove to and needed to be generalized as an universal truth. Positivist research methodology has proven itself as reliable and testable. Positivism research tradition offered universal but partial solutions, such as 'truth', 'objectivity', 'progress,' and 'scientism.'

\section{Research Focus}

The renewal and changes in the research allowed more space for the interpretive research paradigm to emerge to the stage with its subjectivist epistemology based on local and specific realities that required embracing greater degree of ambiguity and unpredictability. New discussion about the research as a holistic and intuitive study took place in Latvia only in recent years. A number of new emerging feminist, postmodern and critical theories become influential in shaping new paradigms in educational research. New forms of qualitative research have emerged alongside with the quantitative research and allowed the researcher to enter the lives of others, to listen to their stories and fears. Some feminist research have challenged the dominant discourses of objective and universal truth by introducing alternative epistemologies that allowed more space for a systematically silenced voices to emerge and to challenge the dominant power structures and inequalities. New forms of research offered liberating experience from the meta - narratives by setting new intellectual challenges and allowing to see knowledge as more contextual, subjective and particular. Though, both approaches have their validity and intrinsic value. The aim of both traditions was to find the truth, by understaning different ways to reach it.

Participatory action research appeared as a new form of research in a knowledge production at the university settings. This also brought about a number of risks of romanticizing the research projects understood as 'activism.' These research projects were of small scale, involving a small group of like - minded researchers and, as a rule, were open - ended, messy and always risky (Maquire, 1993, 1987). Some scholars gave the preference to hold to more 'reliable' positivist universalizing research methodologies, some choose to engage in a qualitative and participatory action research. Few university teachers as post - communist researchers who engaged in carrying out a participatory action research and a narrative research admitted that this type of research is a more powerful tool to reflect uncertainties and issues as small meta narratives emerging at social, political and individual level. They highlighted the issues that were unrevealed by the use of preferred quantitative research traditions in the soviet research tradition. New research traditions required new methods and approaches that allowed more space to capture fluidity and movement (Dean, 2010). 


\section{General Background of Research}

For the purpose of this small scale study the author chooses narrative methodology with the aim to find out the opportunities and tensions of the using qualitative and action research methodologies though the narratives of younger and senior researchers. The aim of the study was to trace changes in research traditions in post soviet educational landscape and to understand how different researchers view truth, knowledge, and a value of one approach to research over others, as influenced by the current and prior ideological, political, institutional and personal contexts. Research paradigms describe a research culture that includes a set of beliefs, values, and assumptions shared by a community of researchers (Johnson \& Onwuegbuzie, 2004). These include ontological and epistemological beliefs of a researcher.

All the participants gave their consent to the data being used for this publication. The author's interpretations of the data were taken back to the participants' inter subjective agreement. Actually, participants' narratives were stories of learning about their learning at a meta - level, that resulted in a more critically reflective approach to their work and research.

\section{Sample of Research}

Among the participants are three $\mathrm{PhD}$ candidates who work as agent faculty members at the university combining both, teaching and research. The other three faculty members who were willing to be part of this research were senior faculty members who had an experience of both, soviet and emerging qualitative research traditions. They reflected upon their choice of research methodologies in their research, and the research of $\mathrm{PhD}$ students they were supervising.

The stories people tell about their research and inform how they do research. The data was gained in semi - structured interviews in a friendly and relaxing environment. Six individual interviews were carried out, both, with doctoral students who are also employed in part time teaching at the university setting, the editor of the journal who is also a staff member and a researcher at the university setting, and three senior staff members who work as supervisors of doctoral student, having both, the experience of doing research within the positivist and qualitative research traditions. The interviews covered such aspects as participant's experience of doing research, their preferred research methodologies, tensions they deal with in their research, as well as nature and extent of their personal learning. Interview questions were formulated, piloted and refined prior to the main interview phase. Interviews were conducted over two month period, lasted $40-60$ minutes. To enhance research neutrality and to encourage them to express openly, the participants were granted anonymity. Key questions addressed in the interview were: tell about your experience of a researcher.

Tell about the latest investigation you were engaged with. What are the methodologies do you use while carrying out your research? What are the main difficulties do you encounter with the methodology you have chosen? Why did you choose the particular methodology? Are there aspects of methodology that create particular difficulties for you? How do you overcome those difficulties? Which methodology do you find more useful in covering you topic of research? Why? Do the research methodologies you use for the current study differs from the one you used before? Do you see any benefits of this methodology? Why was a particular perspective chosen to answer a particular research question? How would the research design be different if they were approached from a different perspective?

\section{Results of Research: the narratives of researchers in post - Soviet space}

$\mathrm{PhD}$ candidates who chose participative action research for their study, told their stories how they have developed their understanding of the research by working as a study group, how they transferred new learning into pedagogical practice and how their research is informed by 
PROBLEMS

OF EDUCATION

IN THE $21^{\text {st }}$ CENTURY

Volume 51, 2013

66

search: personal contexts (what inspired to do research), theoretical contexts (how their research could be related to the existing body of the research), policy context (if the policy enables them to work in a way that was consistent with their values), and the other relevant contexts. New researchers are quite open to a new paradigm of the research that requires generating their own theories leading to more sustainable forms of personal and social development, rooted in freedom (Sen, 1999). As one of the young researchers commented, by using her freedom to create new theories she supports new emerging freedoms of the research participants as well. This is the generation of young researchers who grew up in the conditions of freedom and emerging new paradigms in education and research, therefore they position themselves as free from any past traditions and constraints to experiment with new methodologies of searching for the truth. As McNiff \& Whitehead (2009) concludes, over reliance on external agency means that the system may collapse if the agency is withdrawn, while internal capacity means creation of renewable sources for growth.

New researchers have made their theories public through their research accounts as revealed in their publications and international conferences. As they pointed out, one of the advantages of doing participatory action research is being able to bring about changes not as imposed from above by the external authority but as emerging from within, in accordance with research participants' wishes and desires. Still, even for the beginner researchers this was quite a complicated task, since they had a desire to look for the logic, pre - established order and recipes set by the authorities in the field of study. As Reason \& Goodwin (1999) suggest, since inquiry disturbs established ways of seeing and doing; sufficient order is needed to contain necessary chaos and confusion. Management of anxiety is a core task in action research. According to Gabriel (2005) extensive anxiety may lead to highly dysfunctional defensive routines; it can breed inertia and decay. By overcoming this tension researchers can gradually learn to trust the value of the process, develop the capacity of research participants to think independently, and to decide structure their practice and research. Both new researchers admitted that they are happy to deal with the ambiguities and uncertainties of fluidity of participative action research. Researchers have realized that knowledge may be uncertain and ambiguous, demanding multiple answers. Participation in one year long discussion over building research vocabulary and action research methodology relevant for the issue of their study included the ambiguity of " $n o t$ yet knowing the answer' and caused some tensions among the new researchers at the initial stages of the research. Gradually, as one of the new researchers commented, 'I have learned to create meaning out of the meaning created by the respondents.' Further, young researchers have developed the meta- skills of questioning insights emerging in their research. They described their first steps in overcoming barriers while interviewing their respondents. At the initial stages of the research one can notice a powerful influence of their supervisor. Gradually researchers developed their distinct voice in shaping and furnishing their study. They commented how carrying participative action research developed in them a greater sense of agency and partnership, as well the sense of being able to make a difference. They developed new work patterns leading to greater enrichment as individuals. Gradually they have learned to produce their personal theories by inviting others to learn with them. Stimulating and a supportive research environment allowed a space for the analytical questioning and creativity. As one of the younger researchers commented, while doing research, she has learned to see multiple perspectives and the context of the research participants and has learned to be comfortable with the uncertainty.

One of younger researchers has mentioned a warning expressed by several mentors and leading researchers that there might be a danger of not defending their theses unless they use quantitative research methodology in line with their main method of research - quantitative in order to ensure the validity and reliability of research. Still, they believe that this approach suggested by some senior researchers is degrading and it diminishes the value of a qualitative research. The other participant who is about to defend her theses, has mentioned that she has integrated a significant part of quantitative research in her study in order to ensure the validity 
of her research in eyes of more experienced senior researchers who give the preference to the quantitative studies just to be on a safe side.

Younger researchers described their study as grounded in certain ontological, epistemological and methodological assumptions. Their epistemological assumption leads to the understanding of the research as a process where they view themselves as agents of change. Ontologically, they organized their research in consistency with their values. As the new researchers admitted, carrying out a participant action research for them required creating an 'open communicative space' (Hagerman, 1984) to allow paradoxes and contradictions to emerge. Communicative action allowed testing comprehensibility, accuracy and sincerity of various communicative acts of participants' life worlds (Kemmis, 2001, p. 95). They admitted, that the more they are engaged in scientific readings and critical and reflective processes with their co- researchers, the more intriguing the research becomes, the more nuanced their view becomes about the issue of study.

The senior researcher who have adopted traditional ways of doing research during their career at the University, found it comfortable to look for a fixed outcome with its applicability everywhere. They judged their research in terms of its generalizibility and replicability. For them this was quite difficult to experiment with new forms of gaining knowledge and to view research as evolving story. Senior staff members who were educated in the quantitative research tradition had to deal with some tensions in adopting a research traditions that required them being more flexible and interpretive to a constantly emerging opportunities, since, as they admitted, new forms of inquiry evoke anxiety with its lack of structure, need to experiment with its open - endedness, uncertainty and unpredictability. One of the senior researchers told about a shift in her research as influenced by the positivist ontology and objectivist epistemology based in control over the design, procedure and the outcomes to a more open interpretive paradigm based on contextual realities and a subjectivist epistemology: "I had an urge to strive to a logic of a research design as used by doing quantitative study. I needed to adjust to a different way of doing interpretive kind of studies, while mentoring my students who gave the priority to a qualitative type of studies. I needed to readjust, to change together with my students whom I was mentoring." The senior researcher's narrative revealed the ambiguities she was dealing with while mentoring her doctoral and master program students. As Holmes (2002) argues, they need to look to the 'unasked' questions, and 'renovate' existing patterns of though and practice, by exposing the ideology which underlines them, and to submit them to a rigorous critique' ( $\mathrm{p}$. 77)

Senior researcher's multiple identities of the researcher come to the surface in complex and contradictory relationships of the present and past research traditions, shaped by the interplay of diverse ideologies and trajectories. As she mentioned, having a disposition to a linear and tight research designs, it takes time to adjust to the unpredictability of the interpretative research tradition. Even the younger researchers pointed to the tensions they encountered adjusting to a flexibility of a collaborative research design processes. One of the younger researchers commented about certain ambiguities: "Collaborative action research is different from the research where somebody tells you what the project is going to be; what kind of outcome there will be at the end." ... "The research is always open - ended, where an intuitive feeling guides the process of generating a new conceptualization of the issue of the study." This is a process of unfolding, where the researcher needs to be intuitive in order to capture the evolving meaning. 'It allows to uncover the knowledge participants possess based on their everyday practices and experiences which is essential in a particular context as well as to allow them to be less dependent on outside resources and knowledge.'

A number of scholars have pointed to a mixed method research as best suited to unreveal educational phenomena of „enormous complexity” (Berliner, 2002, p. 20). They point out that both, qualitative and quantitative data can support a stronger scientific inferences compared to their use in isolation. (Feuer, Towne, \& Shavelson, 2002). A mixed method approach can help to establish cross - context patterns of regularity and determine unique within - site vari- 
PROBLEMS

OF EDUCATION

IN THE $21^{\text {st }}$ CENTURY

Volume 51,2013

68

ables (Greene, 2005). Greene (2005) adds that this approach values "multiple ways of knowing and multiple value stances, .... understanding that is woven from strands of particularity and generality, contextual complexity and patterned regularity, inside and outside perspectives, the whole and its constituent parts, change and stability, equity and excellence" (p. 208). The senior participants of this study as the main arguments for the use of mixed method research have mentioned the following considerations: support in explaining quantitative outcomes, understanding in depth how the measures worked in a theoretical model, assessing the context when describing the outcomes.

\section{Conclusions}

Research paradigms are belief systems based on the core philosophies of science, and research traditions, methodological approaches and design strategies that are influenced by paradigms. They serve as a guide in highlighting researchers' assumptions, values and activities in relation to their issue of study. The selection of a research tradition that is congruent with one's research purpose is a criterion of the trustworthiness of one's research.

Decentring approach to research is liberating, this is a search for more just narratives to substitute the ones that proved to be undemocratic as forms of being or not constituting to the betterment of the situation. Such an attitude becomes liberating for the research participants, since it challenges political, economic, institutional ways of production truth.

The current reality indicated to the existence of three legitimate traditions of gaining truth that coexist in academia in Latvia, the one grounded in a positivist research tradition aiming at explaining relations between dependent and independent variables, and the another one of interpretivist tradition, aiming at deeper understanding of experiences and purposes, as well, as the third one of a collaborative action research aimed at changing reality for a better and a more sustainable future. The emerging qualitative research tradition gradually proves itself as legitimate as the quantitative tradition. Though, an increasing number of researchers are making their efforts in integrating qualitative and quantitative methods in mixed research designs in order to answer their research questions. This form of research proves itself to be inclusive and pluralistic. Majority of researchers hold to a measurement based research in its own validity, still some try to connect it to emerging trends in qualitative inquiry.

The development of a culture of research at the Universities should become a habitual disposition of mind of every lecturer rather than seen as a fragmentary teaching strategy. Research should be seen as a link for building connection between the student, the teacher and the subject matter. The working notions of teaching should become: ongoing reflectivity, relational knowing, and a mindful embodiment.

The changes in research traditions have also challenged qualitative researchers' epistemological awareness about a shifting the focus from traditional quantitative research traditions towards alternative ways of doing research. New researchers clearly identified themselves with a qualitative research orientation. Senior participants emphasized that a good research question can be measured quantitatively and/or should describe a causal relationship between the variables. Senior researchers, who gave preference to quantitative research, admitted that they began to appreciate the value of qualitative research methods as a complement to quantitative approaches. Some recognized their lack of training in qualitative methods.

Emerging tradition of a new scholarship of educational enquiry has a considerable potential for new pedagogies to emerge at the University setting. New epistemologies have a potential for developing new organizational cultures of inquiry, new thinking that can support new ways of working. Qualitative action research as practiced by the researchers has proven its generative transformational nature by leading to improve practice as consistent with researchers' values.

The author strongly believes that both traditions have their own intrinsic value in a way to discover the truth, depending on the particular case, the objective and the scope of the study. 


\section{References}

Berliner, D. C. (2002). Educational research: The hardest science of all. Educational Researcher, 31 (8), $18-20$.

Dean, M. (2010). Governmentality: Power and rule in modern society (2 nd ed.). Los Angeles: Sage.

Feuer, M. J., Towne, L., \& Shavelson, R. J. (2002). Scientific culture and educational research. Educational Researcher, 31, 4-14.

Gabriel, Y. (2005). Organizations and their discontents: miasma, toxicity and violation. Available online at htpp://www.mngt.waikato.ac.nz/research/ejrot.cmsconference/2005/proceedings/psychoanalytic/Gabriel.phd (accessed, 2011, December 10).

Greene, J. (2005). The generative potential of mixed methods inquiry. International Journal of Research Method in Education, 28, 207- 211.

Habermas, J. (1984). The theory of communicative action: Reason and the rationalization of society. Boston, MA: Beacon Press.

Hays, D. G., \& Singh, A. (2011). Qualitative inquiry in clinical and educational setting. New York: NY: Guilford.

Johnson, R. B., \& Onwuegbuzie, A. J. (2004). Mixed - methods research: A research paradigm whose time has come. Educational Researcher, 33 (1), 14-26.

Kestere, I. (2005). Pedagogijas vesture. Skola, skolotajs, skolens [History of pedagogy. School, teacher, student]. Riga: Zvaigzne ABC.

Kemmis, S. (2001). Exploring the relevance of critical theory for action research: Emancipatory action research in the footsteps of Jurgen Habermas. In P. Preason \& H. Bradbury (Eds.). Handbook of action research: Participative inquiry and practice. London: Sage, 91 - 102.

Kline, W. B. (2008). Developing and submitting credible qualitative manuscripts. Counsellor Education and Supervision, 47, $210-217$.

Maguire, P. (1993). Challenges, contradictions, and celebrations: Attempting participatory research as a doctoral student. In P. Park, M. Brydon - Miller, B. Hall \& T. Jackson (Eds). Voices of change: Participatory research in the United States and Canada. Westport, CT: Bergin \& Garvey.

Maguire, P. (1987). Doing participatory reserch: A feminist approach. Amerst: Center of International Education.

McNiff, J., \& Whitehead, J. (2009). All you need to know about action research. Thousand Oak, Sage.

Reason, P., \& Goodwin, B. C. (1999) Towards a science of qualities in organizations: Lessons from complexity theory and postmodern biology. Concepts and Transformations, 4 (3), 281 - 317.

Reason, P. \& Torberts, W. R. (2001). The action turn: Towards a transformational science. Concepts and Transformations, 6 (1), 1 - 37.

Rubane, Z., Geikina, L., \& Svence, G. (2008). Implications of totalitarian values in the post - soviet educational space: the theoretical and methodological research basis. In Changing Education in a Changing Society, Klaipeda: Klaipeda University, 4-10.

Rubane, Z. (2010). Topicality of critical thinking in the post soviet educational space. European Education, 41 (4), 24 - 40.

Sen, A. (1999). Development as freedom. Oxford, Oxford University Press.

Zogla, I. (2011). Leading educators' relearning in a post - Soviet country. Theory and Practice, 45 (2), $133-142$.

Advised by Yesudas Choondassery, Berkeley College, Woodland Park, New Jersey, USA

Received: December 27, 2012

Accepted: February 01, 2013

Dzintra Ilisko

PhD, Daugavpils University, 13 Vienibas Street, LV-5401 Daugavpils, Latvia.

E-mail: dzintra.ilisko@du.lv

Website: http://du.Iv/en 